\title{
¿Por qué leer en la Biblioteca del Centro de Estudios en Educación?
}

\section{Título}

La Educación Básica la puerta de entrada para conocer a la Ecología

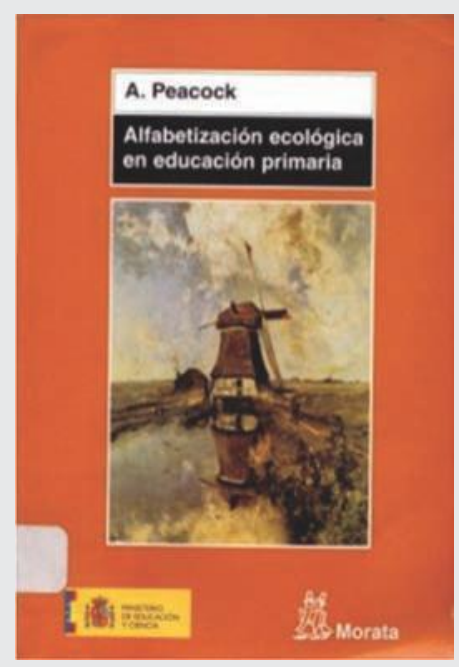

Autor

Libro Alan Peacock

Alfabetización ecológica en educación primaria

Impreso España

- Secretaría General Técnica del

Coeditores Ministerio de Educacion y Ciencia

Fecha 200€Ediciones Morata S. L.

142

\section{Páginas}

\section{Por: Mg. Nicte De Fátima Guajardo Concha}

Este texto pedagógico se encuentra conformado por once capítulos, escritos con un lenguaje propio de la didáctica ya que cuenta con imágenes y cuadros de textos resaltados. En cada una de las páginas se puede apreciar claramente la invitación del autor a los lectores a través de la respuesta a los cuestionamientos planteados en los diversos capítulos del libro. Es un llamado a que se reconozca la importancia que tiene la implementación de conceptos como "ecología" "biodiversidad" y "sostenibili$d a d$ " en el currículum de Educación Básica, con la intención de que los profesores de este nivel tengan las sufcientes herramientas para desarrollar en los niños un pensamiento crítico y refexivo. Tiene también la fnalidad el libro de que ellos mismos puedan hacer elecciones de consumo sostenible pero, sobre todo, que se sientan capaces de abordar esta clase de conceptos con total seguridad.

Recorre el libro que invitamos a leer, la siguiente premisa: "no podemos ayudar a los niños a pensar, aprender y vivir de otra forma si nosotros, sus padres y sus maestros, no tenemos una visión clara de lo que importa realmente" esto porque se considera que es el punto de partida para lograr una verdadera formación integral, ya que para apropiarse de los términos ecológicos, es necesario cambiar nuestra forma no sólo de pensar sino de actuar.

El autor ofrece al fnal de la obra un listado de diversas páginas web, las cuales pueden ser revisadas tanto por profesores como por estudiantes como una fuente de información útil en el desarrollo de sus diversas actividades educativas. 


\section{Título}

La Educación Ambiental entendida desde la interdisciplinariedad

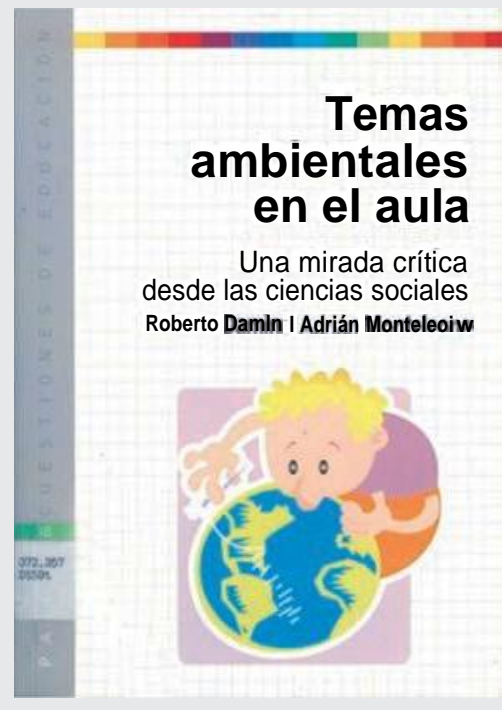

$\begin{array}{ll}\text { Autores } & \text { Roberto Damin } \\ & \text { Adrián Monteleone }\end{array}$

Libro

Temas ambientales en el aula: Una mirada crítica desde las ciencias sociales

Impreso Argentina

Editorial Paidós

Fecha 2002

Páginas $\quad 180$

\section{Por: Mg. Nicte De Fátima Guajardo Concha}

Desde el prólogo María del Carmen Munilla realiza una invitación a los profesores en general, pero de forma específca a quellos que abordan el tema ambiental, para que tomen en cuenta este libro en la preparación de sus clases, ya que como bien dice es importante no impartir una enseñanza fragmentada o superfcial.

Los autores desarrollan los temas de manera didáctica. En el primer capítulo se aborda lo referente a la Educación Ambiental, los autores nos permiten acceder a los antecedentes, además de ayudarnos a saber cómo resaltar la enseñanza de los valores en la educación ambiental, para lo cual es importante que este tema se encuentre incluido dentro del currículo escolar y de forma analítica podamos lograr un verdadero cambio de actitudes ante la urgente demanda de una nueva percepción ambiental, lo que nos ayudará a modifcar nuestras pautas de consumo. Sugieren los autores que necesitamos la perspectiva de las Ciencias Sociales, pues ellas nos permiten enriquecer la mirada tradicional que ha caracterizado a la enseñanza de la Educación Ambiental.

A los docentes nos agrada que nos permitan conocer cómo implementar las estrategias didácticas para el adecuado desarrollo de nuestras clases, así que, esta es la misión del capítulo cuatro. En él, los autores nos permiten conocer cuál es esa ayuda que pueden ser aplicadas en los distintos niveles educativos.

La intención de los autores al incluir el anexo que se localiza a partir de la página 165 , es una buena herramienta que permite conocer cuáles son las organizaciones más importantes que se ocupan del tema ambiental, agregan una lista de libros, así como sitios web comentados brevemente. Los autores proporcionan al lector el acceso a una fuente de información actualizada y especializada que les permita enriquecer su práctica profesional. 


\section{Título}

\section{Leadership \& sustainability}

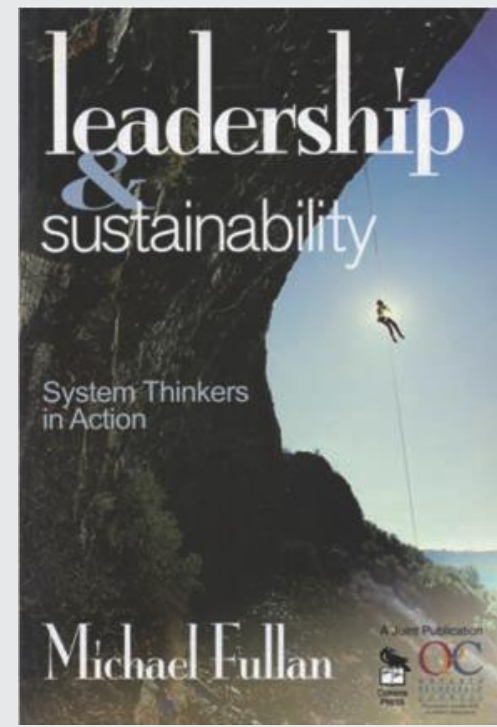

Autor Michael Fullan

Libro Leadership \& sustainability

Impreso Estados Unidos

Editorial Corwing press

Fecha 2005

Páginas 116

\section{Por: Mg. Brenda Isabel López Vargas}

Michael Fullan es uno de los grandes referentes contemporáneos del cambio educativo y los caminos que hay que tomar para lograrlo. Profesor Emérito del Instituto de Estudios en Educación de la Universidad de Toronto, Fullan es actualmente asesor especial del Primer Ministro y del Ministerio de Educación de Canadá. Ha publicado una vasta obra relacionada con el cambio y el liderazgo en las organizaciones educativas, y con las reformas necesarias para mejorar la educación, y varios de sus libros han sido premiados.

En Leadership \& sustainability (Liderazgo y sostenibilidad), nuevamente se acerca al tema del liderazgo y su importancia en el logro de la sostenibilidad de las reformas y los sistemas educativos.

Fullan propone en este texto que el éxito de las reformas educativas en todos los niveles, se relaciona directamente con eso que llamamos la sostenibilidad y con la for- mación de pensadores sistémicos al interior de las organizaciones. Plantea la sostenibilidad como la capacidad de un sistema para comprometerse con las complejidades del mejoramiento continuo, en concordancia con profundos valores humanos; para desarrollarla, entonces, es necesario crear una masa crítica de líderes que se comprometan a actuar cotidianamente para generar los cambios necesarios, pensados sistémicos en acción, personas comprometidas con hacer mejor las cosas, quienes a la vez infuyen en otras para alcanzar mejores logros.

Desde la perspectiva de la educación ambiental que asumimos, este planteamiento es esencial para alcanzar los cambios culturales que requerimos, tanto al interior de las instituciones educativas como en las organizaciones sociales en su conjunto, para construir sociedades sustentables.

Por su estilo ágil y su propuesta provocadora, es una lectura sumamente recomen- 
dable para profesores de todos los niveles del sistema educativo y especialmente para directivos y aquellos quienes trabajan en la formación docente. 